Research Article

\title{
Analysis of the Spatial and Temporal Differences of China's Power Carbon Footprint
}

\author{
Zhen-Yu Zhao $\mathbb{D}^{1},{ }^{1}$ Shu-Guang Yuan $\mathbb{D}^{1},{ }^{1}$ Yu Fu, ${ }^{1}$ Ying Wang, ${ }^{2}$ and Heng $\mathrm{Li}^{2}$ \\ ${ }^{1}$ Beijing Key Laboratory of New Energy and Low-Carbon Development, School of Economics and Management, \\ North China Electric Power University, Beijing 102206, China \\ ${ }^{2}$ Department of Building and Real Estate, The Hong Kong Polytechnic University, Hong Kong, China \\ Correspondence should be addressed to Zhen-Yu Zhao; zhzhy@ncepu.edu.cn and Shu-Guang Yuan; bolun001@126.com
}

Received 15 December 2019; Revised 4 March 2020; Accepted 25 March 2020; Published 14 April 2020

Academic Editor: Andrea Bonfiglio

Copyright (c) 2020 Zhen-Yu Zhao et al. This is an open access article distributed under the Creative Commons Attribution License, which permits unrestricted use, distribution, and reproduction in any medium, provided the original work is properly cited.

\begin{abstract}
Thermal power generation has increased $\mathrm{CO}_{2}$ emissions, which in turn has put tremendous pressure on the environment. Therefore, analyzing the regional ecological environmental carrying capacity of thermal power carbon emissions is of great significance for countries with high thermal power capacity to guide the development of low-carbon power and industrial layout. To accurately measure the pressure of regional power production for the environment, this paper proposes the concept of renewable energy virtual carbon emission based on the carbon footprint theory. The regional power carbon footprint (PCF) depth model and the regional power carbon deficit model are constructed. Moreover, through the statistics of China's power production, this paper calculates the depth of China's PCF and analyzes the temporal and spatial differences of China's PCF depth from the three aspects of regional power installation structure, power deficit, and PCF transfer. The results obtained illustrate, firstly, that China's overall PCF continues to increase, with the depth of PCF moving eastward. Secondly, due to the imbalance of China's PCF, there are significant temporal and spatial differences in the depth of regional PCF. Thirdly, with the rapid development of renewable energy in China, the effect of controlling the depth of regional PCF by renewable energy is rising. Besides, the transfer of PCF among different China's regions has significant impact on the change of PCF depth of power output provinces.
\end{abstract}

\section{Introduction}

According to the report of the International Energy Agency (IEA), China has become the world's largest energy consumer. In 2018, the total energy consumption of the country reached 4.62 billion tons of standard coal, and fossil energy accounted for $85.7 \%$ [1]. China is also the most significant GHG (Greenhouse Gas) emitter, accounting for $27 \%$ of global GHG emissions [2]. To reduce fossil energy consumption and GHG emissions, the Chinese government promised that the total amount of carbon emission(CE) will not increase by 2030, and the $\mathrm{CE}$ intensity will be reduced to $60-65 \%$ compared with that of 2005 [3].Therefore, China is currently encountering the huge CE reduction pressure. In recent years, the Chinese government has adjusted the energy consumption structure and the layout of the energy industry. However, the current energy structure in China is still dominated by fossil energy [4]. In 2018, China's total raw coal consumption was 3.77 billion tons, $70 \%$ of which was used for thermal power generation. The $\mathrm{CE}$ in the process of thermal power production was 4.2 billion tons, accounting for $40 \%$ of China's total CE [5]. Thus, it can be seen that the power sector is the source of CE. Therefore, exploring a low-carbon development approach of power is significant to achieve China's CE reduction goals.

In order to reduce energy consumption and $\mathrm{CE}$ of power production, China has implemented a series of countermeasures, such as installing ultralow-emission equipment for thermal power plants, replacing high-emission thermal power generators with new low-emission units. However, the rapid development of China's economy requires huge power, and this production structure of high proportion thermal power poses a great pressure to $\mathrm{CE}$ reduction. Besides, the power production and demand of China are 
mismatched obviously in its territorial space. Regional environment and emission issues have become primary consideration factors for local government to plan and develop regional electricity system [6-8]. Therefore, it is necessary to explore how to scientifically assess the CE level and ecological environmental carrying capacity of thermal power in different regions.

Nowadays, the carbon footprint has become an essential concept for assessing the impact of human activities on the ecological environment [9], and it was mainly used to measure GHG emissions [10]. Combining the concept of carbon footprint with different energy research objects could be used to study the effect of CE on the ecological environment from different perspectives, such as fossil energy footprint [11], nuclear energy footprint [12], clean energy footprint [13], wind energy footprint [14], and solar energy footprint [15].

The popular method for determining the carbon footprint involves calculating the $\mathrm{CE}$ amount from energy utilization or converting $\mathrm{CE}$ amount into an equivalent bioproductive land area [16]. Because the bearing capacity level is usually measured by the area of bioproductive land, the method of converting carbon footprint into the bioproductive land area is more suitable to evaluate a region's sustainable development [17-19]. The investigation methods of carbon footprint mainly include life cycle assessment [16], emission inventories factor [20], input-output analysis [11-13, 21], and ecological footprint calculators [22].

At present, there are a few studies related to the research on the power carbon footprint (PCF). Regarding the PCF calculation, literature [23] adopted the life cycle assessment method to explore the PCF of thermal power plants. Literature [24] employed a matrix model containing system interaction effects to calculate the inventory of power generation inputs and then measured the $\mathrm{CE}$ of thermal power generation in China. Study [25] took thermal power, hydropower, nuclear power, and wind power as research objects to calculate the $\mathrm{CE}$ of China's terminal power consumption. They further combined the carbon sequestration capacity of surface plants with the CE to calculate the bioproductive land area index needed to absorb the power $\mathrm{CE}$, which is the PCF.

Regarding the research on the environmental pressure of PCF, literature [26] defined the ratio of PCF to productive land area as the ecological pressure of PCF; the larger the index, the higher the impact of power consumption on the ecological environment. In the process of power generation, the carbon emission intensity of different power sources is quite different. Therefore, the types of power sources need to be considered in the calculation of PCF, mainly involving thermal power, hydropower, and nuclear power [27]. Compared with the measurement of carbon footprint intensity and ecological stress, the evaluation of the carbon footprint change trend is a dynamic study. Considering different power generation types, literature [28] used the ecological network analysis method to quantify the interprovincial $\mathrm{CO}_{2}$ transfer in the transmission and distinguished the control intensity of each province under different $\mathrm{CO}_{2}$ flows. Literature [29] used a gravity model to analyze the change trend of the global carbon footprint of fossil energy and the carbon footprint of fossil energy per capita between 1997 and 2016. The process of transregional power transfer is not only the process of virtual carbon footprint transfer, but also the process of virtual water transfer [30].

From the existing research on carbon footprint, the current measurement of PCF is mainly focused on fossil energy power generation. Although there was a small amount of literature to discuss the renewable energy footprint, the understanding of the renewable energy footprint was not accurate. These studies underestimated the role of renewable energy in replacing fossil energy and its impact on regional CE carrying capacity. In fact, with the increase of the proportion of renewable energy power, renewable energy has a significant contribution to alleviating the pressure of regional power $\mathrm{CE}$ on the environment. Therefore, it is difficult to accurately assess the impact of regional renewable energy power on the environment using the existing research methods.

This paper aims to evaluate the impact of power $\mathrm{CE}$ on the environment and provide guidance for power $\mathrm{CE}$ reduction and power planning. Based on the carbon footprint theory, this paper took the ratio of regional PCF and regional CE carrying capacity as the depth of regional PCF. Moreover, the depth model of PCF was used to measure the temporal and spatial differences of the depth of China's regional PCF. From the time and space dimensions, this paper analyzed the impact of power production structure, power demand, and carbon footprint transfer on the depth of regional PCF. The main innovation of this study is to integrate the virtual carbon footprint of renewable energy into the regional CE capacity. This paper will establish the relationship between renewable energy and environmental pressure of power CE by constructing the depth model of PCF. Besides, the impact of renewable energy on the depth of regional PCF will also be investigated from the perspective of time and space.

\section{Research Methodology}

2.1. Research Framework. This paper mainly consists of two parts: model and case study. The method and process are shown in Figure 1.

The calculation method of power CE is the key work of constructing PCF and power carbon deficit. In the model part, this paper used a bottom-up method to calculate the regional power $\mathrm{CE}$. Combined with the statistics of the annual power generation of each thermal power unit, the coal consumption level of different types of units was used to calculate the regional power generation. In addition, the method of calculating the virtual CE of renewable energy was proposed. In order to measure the pressure of regional power production on the environment, this paper proposed to convert the virtual CE of renewable energy into the virtual PCF and regarded it as a part of the CE carrying capacity.

In the part of case study, this paper calculated the depth of PCF of each province based on China's power production and ecological data from 2007 to 2018. And then, the paper 

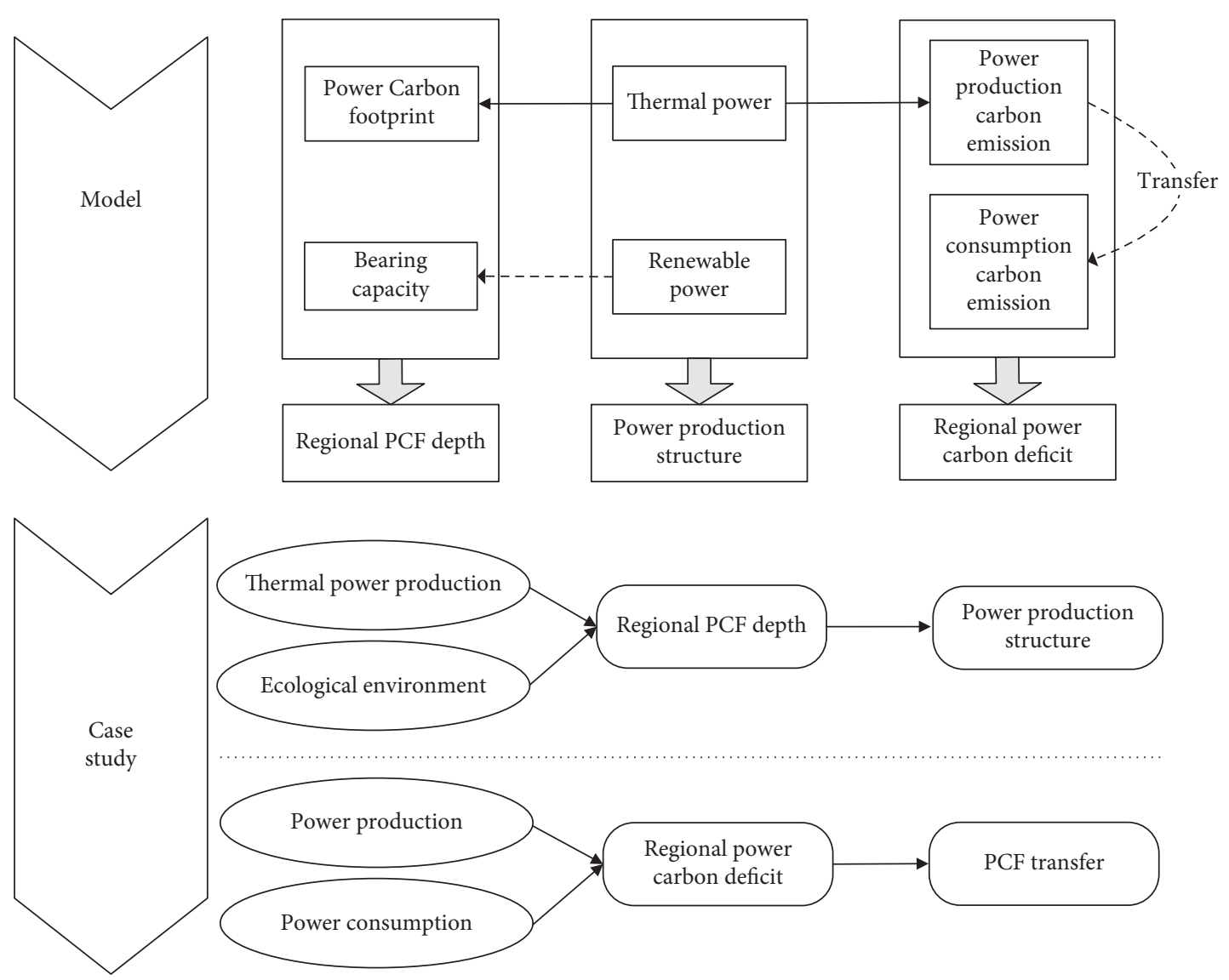

FIGURE 1: The research process of China's power carbon footprint.

analyzed the differences of regional PCF depth according to the power production structure between 2008 and 2018 . Finally, the level of power carbon deficit in each province was measured according to the regional power production and consumption in 2008 and 2018, and the influence of PCF transfer on the depth of PCF was analyzed. Through the analysis of spatial and temporal dimensions, the causes of the great spatial and temporal differences in China's PCF were found.

\subsection{Carbon Emissions from Power Generation}

\subsubsection{Carbon Emissions from Thermal Power Generation.} The CE of power generation mainly refers to the CE of coal, oil, natural gas, and other fossil fuel combustion in the process of thermal power production. In addition to the direct $\mathrm{CE}$ of production process, the $\mathrm{CE}$ of power generation also includes the implicit CE $[11,21]$. For example, CE from fuel processing and transportation are implicit CE. To measure the total CE accurately, the implicit CE should be taken into account when calculating the full $\mathrm{CE}$ of the power generation process. The calculation method of CE of thermal power unit is as follows:

$$
\begin{aligned}
\mathrm{TE}_{i j} & =Q_{i j} \cdot \lambda_{j}+Q_{i j} \cdot \lambda_{j}^{*}, \\
\lambda_{j} & =c \times F_{\mathrm{ce}},
\end{aligned}
$$

where $\mathrm{TE}_{i j}$ is the CE of unit $j$ in $i$ power plant $(\mathrm{t}), Q_{i j}$ is the generating capacity of unit $j$ in $i$ power plant $(\mathrm{kWh}), \lambda_{j}$ is the CE coefficient for unit $j(\mathrm{~g} / \mathrm{kWh})$, and $c$ is the fuel consumption for power generation. For coal-fired units, the index refers to the coal consumption rate of power generation $(\mathrm{g} / \mathrm{kWh})$, and for gas-fired units, the index refers to the gas consumption rate of power generation $\left(\mathrm{m}^{3} / \mathrm{kWh}\right), F_{c e}$ is the CE coefficient of fuel. According to literature [31], for raw coal, the coefficient is $1.9003 \mathrm{~kg}-\mathrm{co} 2 / \mathrm{kg}$; for natural gas, the coefficient is $2.1622 \mathrm{~kg}-\mathrm{co} 2 / \mathrm{m}^{3} . \lambda_{j}^{*}$ is the implicit CE coefficient for unit $j(\mathrm{~g} / \mathrm{kWh})$. According to literature [32], the implicit CE accounts for $5.8 \%$ of direct $\mathrm{CE}$ in thermal power production process.

Then, the total carbon emission of $i$ power plant is

$$
\mathrm{TE}_{i}=\sum \mathrm{TE}_{i j} .
$$

For $m$ area, the total CE of all thermal power plants is

$$
\mathrm{TE}_{m}=\sum \mathrm{TE}_{i} \text {. }
$$

Then, the regional average CE coefficient of thermal power generation in area $m$ is

$$
\bar{\lambda}=\frac{\sum \mathrm{TE}_{i}}{\sum \mathrm{Q}_{i}},
$$

where $Q_{i}$ is the generation capacity of the $i$ power plant $(\mathrm{t})$. 
2.2.2. Virtual Carbon Emission from Renewable Energy Power Generation. Assume that there is only thermal power in a region, and the actual CE is a fixed value at a specific output level. This fixed value is set to the theoretical value of $\mathrm{CE}$ at this demand level. If the power demand is maintained and some thermal power in the region is replaced with renewable energy, the actual CE in the region will be decreased accordingly. The difference between the actual CE and the theoretical value of regional power generation $\mathrm{CE}$ is the contribution of renewable energy emission reduction.

Renewable energy generation replaces the same amount of thermal power and saves fuel, which is equivalent to reducing the carbon footprint of regional power. To distinguish the direct $\mathrm{CE}$ of thermal power generation, this study defines this part of the carbon footprint as "virtual carbon emissions (VCE)." Measuring VCE is conducive to considering the contribution of renewable energy power generation in an all-round way.

There are many types of renewable energy power generation, and different types of renewable energy sources have different CE levels. Also, in different regions, the CE levels of the power generation of different thermal power plants vary greatly. Therefore, it is challenging to count the VCE from the perspective of emission sources. Besides, from the perspective of alternative thermal power, the VCE can be calculated based on the total renewable energy power generation and the regional average thermal CE coefficient:

$$
\mathrm{VCE}_{m}=\bar{\lambda} \cdot \mathrm{RE}_{m},
$$

where $\mathrm{VCE}_{m}$ is the virtual carbon emissions in area $m(\mathrm{t})$ and $\mathrm{RE}_{m}$ is the total renewable energy power generation in area $m$ (kWh).

2.3. Power Carbon Footprint Pressure. The PCF pressure is defined as the ratio of the $\mathrm{CE}$ to the productive land area. It reflects the pressure of CE on natural ecosystems. This index represents the pressure of power consumption on resources and the ecological environment [26].

2.3.1. Power Carbon Footprint Intensity. In this paper, the land area is employed as the unit to measure the carbon footprint. The carbon footprint intensity of power is the ratio of total $\mathrm{CE}$ and net primary productivity of power production.

During the earth's carbon cycle, most of the land surface has carbon absorption ability because of vegetation coverage. The carbon absorption capacity of different land types can be characterized by net primary productivity of vegetation on the surface, which means the organic dry matter production of green plants after deducting autotrophic respiration part in unit time and area [11]. The average net primary productivity of regional land cover is obtained by weighting the area of each species and the corresponding net primary productivity [33]. The formula is as follows:

$$
\overline{\mathrm{NPP}}_{m}=\frac{\sum A_{i} \cdot \mathrm{NPP}_{i}}{\sum A_{i}},
$$

where $\overline{\mathrm{NPP}}_{m}$ is the regional average net primary productivity ( $\mathrm{t} /$ hectare meter $\left.{ }^{2}\right), A_{i}$ is the net primary productivity corresponding to ecosystem type $i\left(\mathrm{t} /\right.$ hectare $\left.^{2} \mathrm{~meter}^{2}\right)$, and $\mathrm{NPP}_{i}$ is the area of class $i$ land (hectare meter ${ }^{2}$ ).

According to the definition of PCF [16], the regional PCF is determined as the area of bioproductive land needed for $\mathrm{CE}$ from power production in the absorption region, and the formula is presented below:

$$
\mathrm{PCF}_{m}=\frac{\mathrm{TE}_{m}}{\overline{\mathrm{NPP}_{m}}}
$$

where $\mathrm{PCF}_{m}$ is the carbon footprint of power in area $m$ (hectare meter ${ }^{2}$ ).

\subsubsection{Carbon Emission Carrying Capacity. Eco-carrying} capacity is an important criterion to measure sustainability in footprint theory. It is expressed by the area of eco-productive land used to support human consumption of ecological services and can be used to quantify the regenerative capacity of a region to provide human available ecological resources and services. Based on the carbon absorption function of land and the idea of carbon absorption and transformation in the ecological footprint method, the land ecological carrying capacity of fossil energy is fixed as the ecological production area that can be provided by the region to absorb $\mathrm{CO}_{2}$ [14]. Based on regional land equilibrium factor and conversion factor, the CE carrying capacity model is as follows:

$$
\mathrm{BC}_{\mathrm{fel}}=c f_{\mathrm{fel}} \cdot \sum A_{i} \cdot r_{i},
$$

where $\mathrm{BC}_{\mathrm{fel}}$ is the ecological carrying capacity of fossil energy land $\left(10^{6}\right.$ hectare meter $\left.{ }^{2}\right), c f_{\text {fel }}$ is the energy conversion factor, and $r_{i}$ is the equilibrium factor of the ecological productive land of type $i$.

The regional carbon dioxide emission bearing capacity, i.e., the ecological carrying capacity of fossil energy land, refers to the total ecological productive area that can be provided by region for absorbing carbon dioxide [34, 35]. The ecological carrying capacity of fossil energy land is calculated based on the carbon dioxide absorption method; the area of all types of ecological production land in the region is the supply of fossil energy land. Renewable energy such as hydroelectricity, wind power, solar energy, and geothermal energy does not emit carbon dioxide in the process of power generation. Considering the alternative role of renewable energy for thermal power, this part of renewable energy power generation theoretically reduces the demand for ecological production land area used to absorb carbon dioxide. Therefore, according to the unit of power generation and coal consumption, this part of renewable energy power generation can be converted into corresponding land area for biological production. In [36], the researchers calculated a corresponding reduction in the area of forest land used to absorb carbon dioxide emitted from standard coal combustion, according to the regional renewable energy power generation. This part of forest land area is combined with the actual forest land area and used to calculate the ecological carrying capacity of the regional 


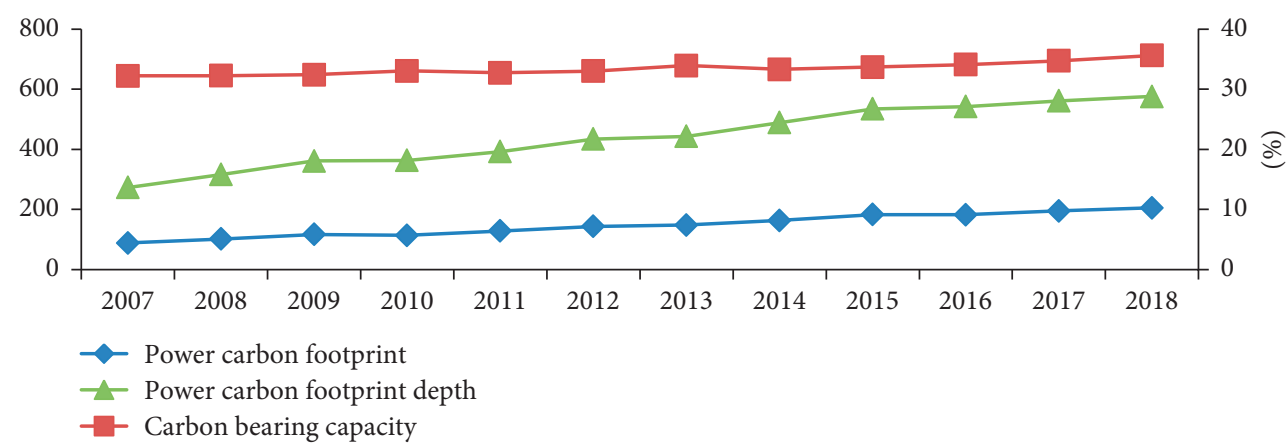

Figure 2: The trend of PCF depth in China from 2007 to 2018. Note. The left ordinate reflects the power carbon footprint and carbon bearing capacity, and the right ordinate reflects the power carbon footprint depth. The unit of the PCF and carbon bearing capacity is $10^{6} \mathrm{hm}^{2}$.

TABle 1: Power carbon footprint depth classification standard.

\begin{tabular}{lc}
\hline Interval & Level \\
\hline $0.00-0.05$ & $L$ I \\
$0.05-0.15$ & $L$ II \\
$0.15-0.30$ & $L$ III \\
$0.3-0.55$ & $M$ I \\
$0.55-0.75$ & $M$ II \\
$0.75-0.1$ & $M$ III \\
$1.0-1.15$ & $H$ I \\
$1.15-1.5$ & $H$ II \\
$1.5-$ & $H$ III \\
\hline
\end{tabular}

$L$ : little; $M$ : middle; $H$ : high.

fossil energy land. However, unlike the calculation of PCF by converting fossil energy power generation to bioproductive land area, the calculation of power CE carrying capacity by converting renewable energy power generation to bioproductive land area is theoretical. There is no such part of ecological productive land area in practice. Therefore, the significance of renewable energy power generation to the environment is to reduce the actual PCF and increase the power CE carrying capacity. Since the CE of renewable energy power generation and the converted land area of ecological production are theoretical values, the carbon footprint of renewable energy power can be defined as a virtual carbon footprint, which could increase the regional CE capacity. According to the transformation idea of [36], the calculation of the virtual carbon footprint of renewable energy is as follows:

$$
\mathrm{VCF}_{\mathrm{RE}}=\sum \frac{\mathrm{RE}_{i} \cdot E_{W} \cdot H_{\text {coal }}}{\overline{\mathrm{EP}_{\text {coal }}}} \cdot r_{\text {Forest }},
$$

where $\mathrm{RE}_{i}$ is the generation capacity of the corresponding renewable energy $i$ in a region $(\mathrm{kW} \cdot \mathrm{h}), E_{W}$ is the coal consumption per unit of the average coal power generation in China ( $360 \mathrm{~g} / \mathrm{kW} \cdot \mathrm{h}), \mathrm{H}_{\text {coal }}$ is the conversion coefficient of $\mathrm{CO}_{2}$ mass released from standard coal combustion (as 2.4925), $\overline{\mathrm{EP}_{\text {coal }}}$ is the average absorptive capacity of global forests for $\mathrm{CO}_{2}$ emissions from coal combustion $\left(6.583 \mathrm{tC} \cdot \mathrm{hm}^{-2} \cdot \mathrm{a}^{-1}.\right)$, and $r_{\text {Forest }}$ is the equilibrium factor of forests.

Therefore, the calculation formula of the ecological carrying capacity of fossil energy land is as follows:

$$
\mathrm{BC}_{m}=\mathrm{BC}_{\mathrm{fel}}+\mathrm{VCF}_{\mathrm{RE}}
$$

\subsubsection{Carbon Footprint Depth of Regional Power Production.} The ratio of ecological footprint to ecological carrying capacity is considered as the concept of footprint depth [10], and the index can be used to evaluate ecosystem security. A regional PCF depth model is established to assess the pressure of the power $\mathrm{CE}$ on the regional environment. The larger the PCF value, the higher the impact of power generation on the regional ecological pressure.

$$
\mathrm{CFD}_{m}=\frac{\mathrm{PCF}_{m}}{\mathrm{BC}_{m}}
$$

where $\mathrm{CFD}_{m}$ is the carbon footprint depth of regional power production in area $m$.

2.4. Power Carbon Deficit. Due to the spatial distribution differences of energy resources and demand, the power production in some regions is less than the power demand, and these regions are known as the power deficit regions. The balance of power production among regions needs to transmit power across regions through transmission lines. Besides, satisfying the energy demand of the power import region usually increases the power generated amount and environmental pressure of the power export region. Therefore, the electricity transmission among different regions could cause the transfer of regional PCF. To some 


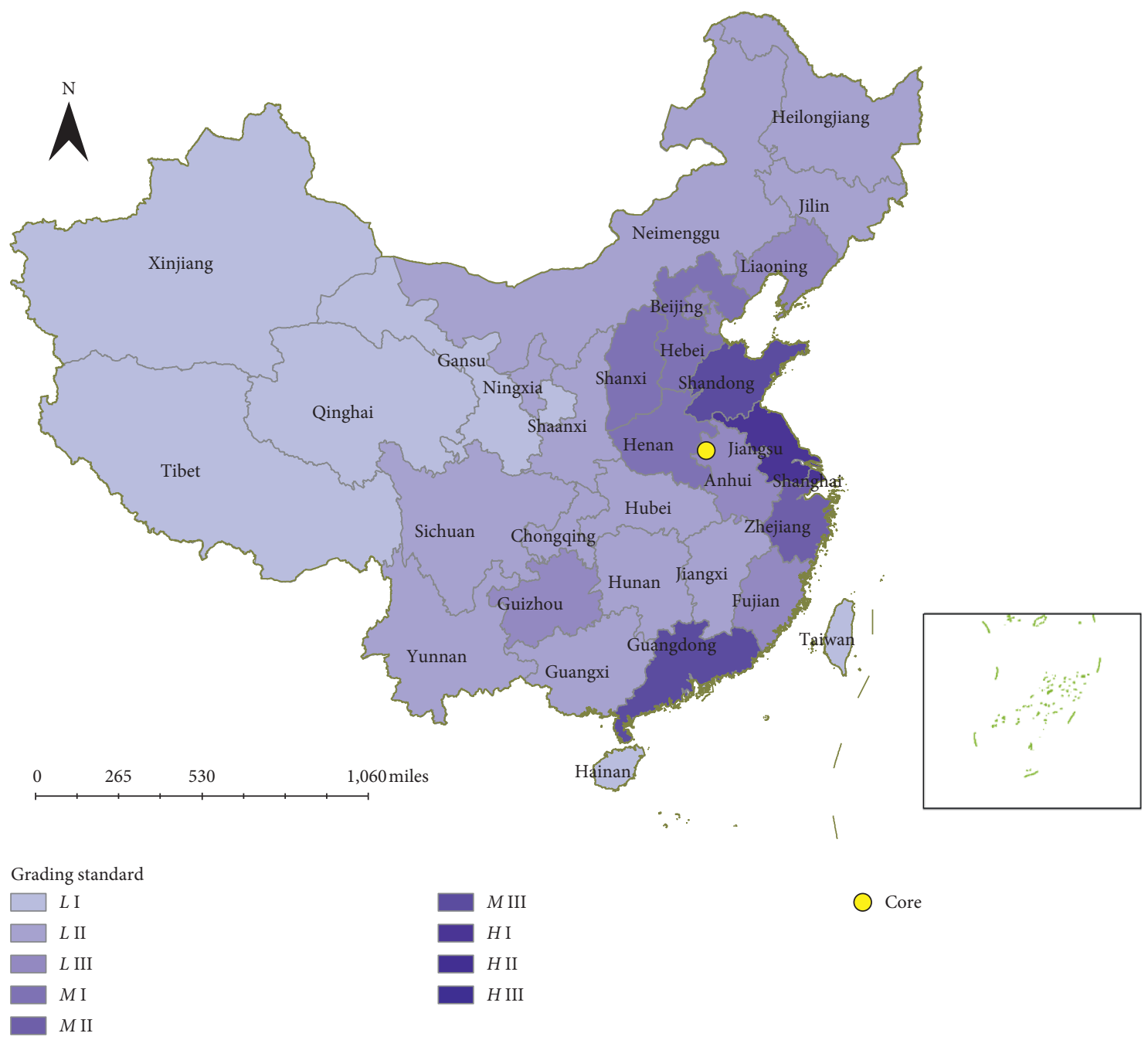

Figure 3: Depth distribution map of power carbon footprint of China's provinces in 2008. Note. The yellow dot is the average center, i.e., density center, calculated according to the power carbon footprint and coordinates of each province, which is used to represent the concentration area of carbon footprint. The principle and calculation method of the geographical average center can be found in literature [41].

extent, the analysis of power carbon deficit can explain the spatial-temporal differences in the regional PCF depth.

To accurately measure the transfer relationship of carbon footprint, this paper proposes the power carbon deficit model based on the concept of ecological deficit [18] and the measurement method of CE quality. For region $m$, its electricity carbon deficit is calculated as follows:

$$
\text { Deficit }_{m}=\overline{\lambda_{C}}\left[\mathrm{CE}_{m}-\left(\mathrm{TE}_{m}+\mathrm{VCE}_{m}\right)\right] \text {, }
$$

where Deficit $_{m}$ is the regional power carbon deficit in $m$ region $(t), \bar{\lambda}_{C}$ is the national average CE coefficient of electric power (t/kWh), and $\mathrm{CE}_{m}$ is the power consumption in $m$ region (kWh).

\section{Data Sources}

The calculation for regional PCF depth requires the acquisition of regional power production data and the data on the land area required for regional biological production.
The regional power production data is mainly the annual power generation of all generating units, which is taken from the National Generating Unit Manual [37] issued by China Power Reliability Management Center. In addition, considering the availability of data, the data on land area required for regional biological production includes forest land area, grassland area, and crop sown area. This part of data is collected from the China Statistical Yearbook [38]. When calculating the regional PCF, the coal consumption of different types of generating units shall refer to the China's Power Industry Development Report [39] issued by the China Electricity Council in that year.

In order to prove the relationship between the regional power installation structure and the depth of PCF, this paper needs to compare and analyze the power sources structure of China's different provinces (cities) in 2008 and 2018, and these data are processed according to the statistical data from the Statistical Data Collection of Electric Power Industry [40] issued by China Electricity Council. 


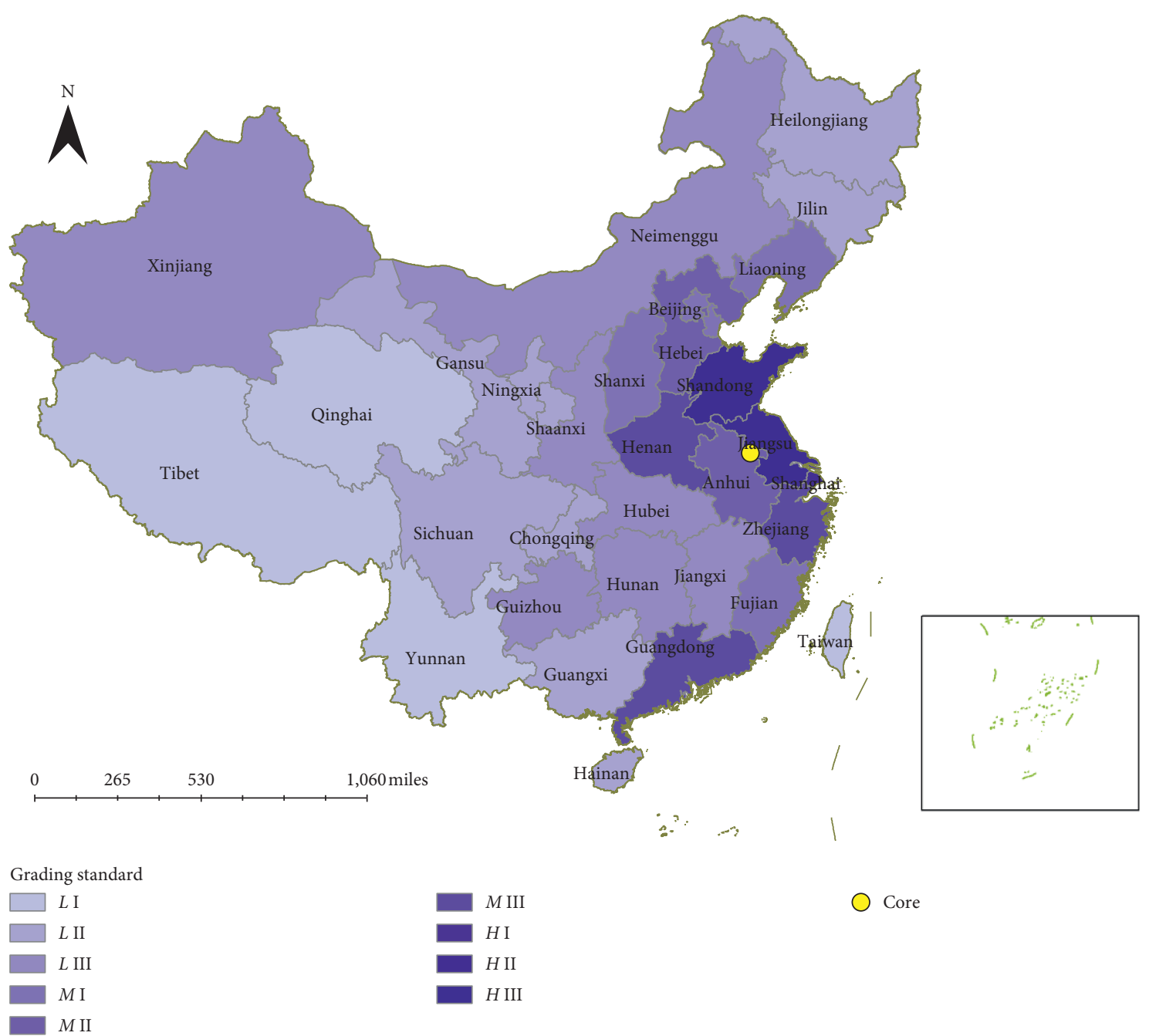

Figure 4: Depth distribution map of power carbon footprint of China's provinces in 2018.

In addition to power production data, the calculation of regional power carbon deficit also requires power consumption data, which is taken from the official website of the National Bureau of Statistics of China. Moreover, when describing the transfer of PCF, the data are sorted out according to the transregional power transmission scale and the actual transmission line path in current year, and the arrow represents the direction of cross-regional transmission. The data of transregional power transmission scale come from literature [39].

The above data do not include data from Hong Kong, Macau, Taiwan, and Tibet. Therefore, these four regions were not included in the spatial differences analysis of China's PCF.

\section{Analysis of Power Carbon Footprint Depth in China}

4.1. Measurement of Regional Power Carbon Footprint Depth in China. Referring to (2), (5), and (6), China's PCF was obtained. And referring to (7)-(9), China's CE carrying capacity was obtained. Based on (10), the PCF depth of China was drilled, as shown in Figure 2.

China's PCF illustrates an upward trend from 88.02 in 2007 to 182.08 in 2018, and the average annual growth rate is $8.11 \%$. The overall upward tendency of bearing capacity is relatively slow, the value increased from 644.52 to 681.61 between 2007 and 2018, and the average annual growth rate is $0.92 \%$. Therefore, the depth of PCF also increases rapidly, its value increased from $13.65 \%$ to $28.77 \%$ in the period of 2007-2018, and the average annual growth rate is $7.24 \%$.

In order to facilitate the comparison of the depth of PCF among regions, this paper adopted the natural breakpoint method to divide the measurement results of each province into nine levels. The grading standards are presented in Table 1.

The results of the PCF depth of China's different provinces (cities) in 2008 and 2018 were graded in terms of the grading standards, and the spatial distribution differences of China's provincial PCF depth were demonstrated, as shown in Figures 3 and 4. 


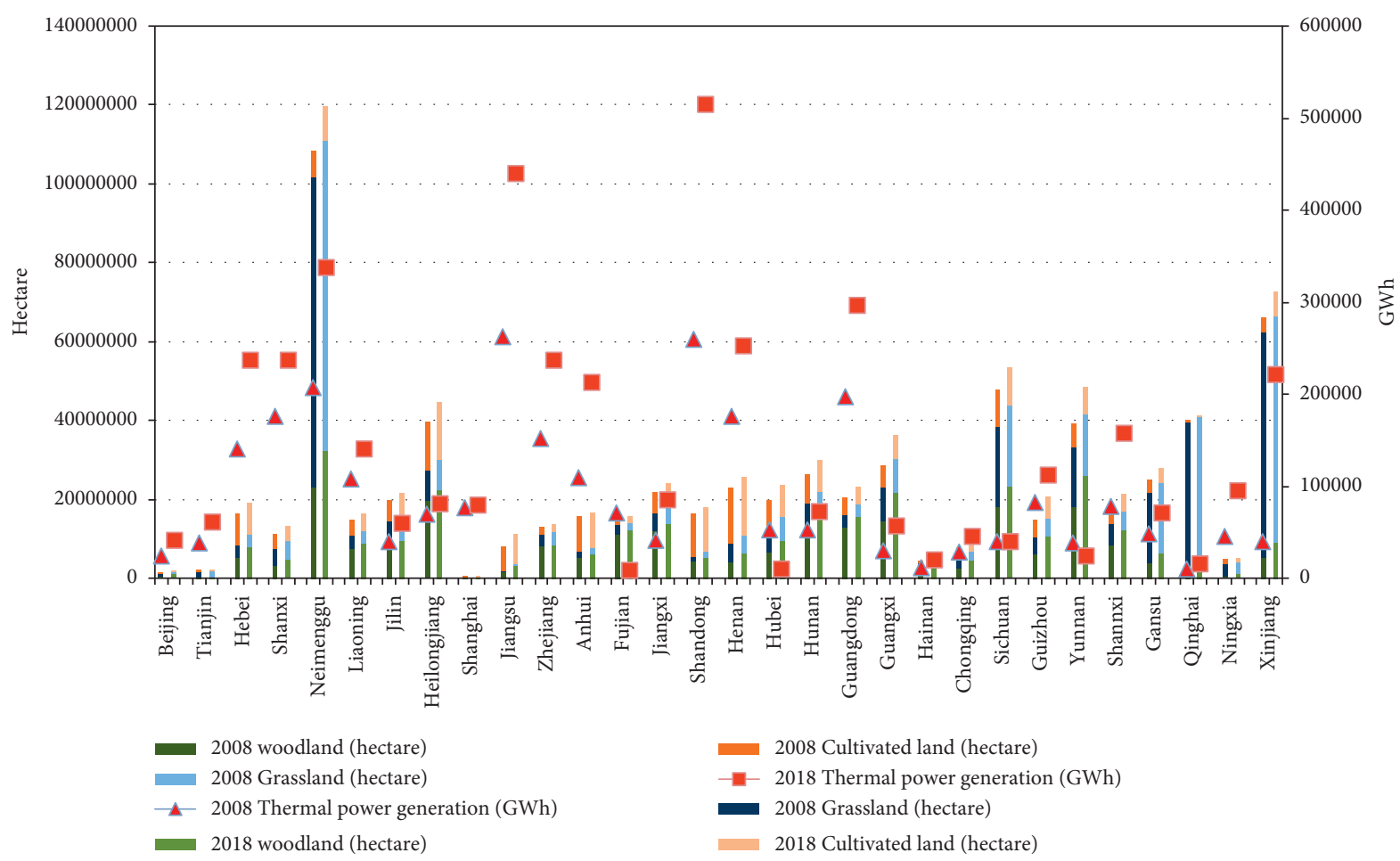

FIgURE 5: Thermal power generation and bioproductive land areas in China's provinces in 2008 and 2018.

As seen in Figure 3, there is a clear spatial agglomeration of China's PCF in 2008, with low-value areas concentrated in northwestern China and high-value areas concentrated in eastern China. In 2008, only the Jiangsu and Shanghai provinces are in the $H$ I level; in the $M$-level, there are six provinces, namely, Shanxi, Henan, Hebei, Zhejiang, Guangdong, and Shandong; the remaining regions are in an $L$ grade, of which Qinghai, Hainan, Xinjiang, and Gansu belong to the $L$ I grade.

It can be seen from Figure 4 that, in 2018, Shandong's PCF depth is close to 1.5 , entering the $H$ II level. Jiangsu's carbon footprint depth reaches 1.55, entering the $H$ III level. Beijing, Tianjin, Liaoning, Fujian, and Anhui rank among $\mathrm{M}$ grades, and the number of $M$ grade provinces has expanded to 10 . Among the $L$ grade provinces, the number of $L \mathrm{I}$ provinces has decreased to 2 .

Comparing Figures 3 and 4, we find that the PCF depth of China has changed dramatically from 2008 to 2018, except for Qinghai's PCF depth, which remains almost unchanged within ten years; the PCF depth of northwest provinces such as Xinjiang, Gansu, Ningxia, and Shaanxi has significantly deepened. Also, the PCF depth of the eastern and southern coastal provinces has been deepened to varying degrees. On the contrary, the PCF depth of Sichuan and Yunnan decreased by $30 \%$ and $50 \%$, respectively, in the past ten years, causing the low-value clusters to shift from northwest to southwest gradually. The above changes show that the core of gravity of China's PCF depth (yellow point in Figures 3 and 4) moves eastward.

According to the definition of the PCF depth, the factors that determine the depth of regional PCF are mainly the regional $\mathrm{CE}$ carrying capacity and the intensity of regional
PCF. The regional CE carrying capacity is determined by the biomass production land area, whereas the intensity of PCF is mainly determined by the thermal power generation. The areas of bioproductive land and thermal power generation of China's provinces in 2008 and 2018 are shown in Figure 5.

It can be seen from Figure 5 that, compared with 2008, the area of bioproductive land in each region changes less in 2018, whereas thermal power production in most regions increases significantly in 2018. The growth of thermal power generation in Inner Mongolia, Jiangsu, Guangdong, and Shanxi provinces is higher than $30 \%$, and the growth of thermal power generation in northwestern provinces of Shanxi, Xinjiang, and Ningxia exceeds $100 \%$. Therefore, the cause of the temporal and spatial differences in the PCF depth of China is the rough time and space of thermal power generation.

4.2. The Impact of Regional Power Installation Structure on Power Carbon Footprint. The regional PCF depth can reflect the balance degree of regional power $\mathrm{CE}$ and $\mathrm{CE}$ carrying capacity. The deeper the regional PCF is, the higher the power CE exceeds the upper limit of the ecological carrying capacity. It is necessary to achieve balance by adjusting the $\mathrm{CE}$ from thermal power production. From the perspective of power production, the main factor determining the regional thermal power production is the regional thermal power capacity. In order to explore the impact of regional power installations on the PCF, regional power capacity maps are produced based on local thermal power installations, renewable energy installations, and PCF depths in 2008 and 2018 (as shown in Figures 6 and 7). 


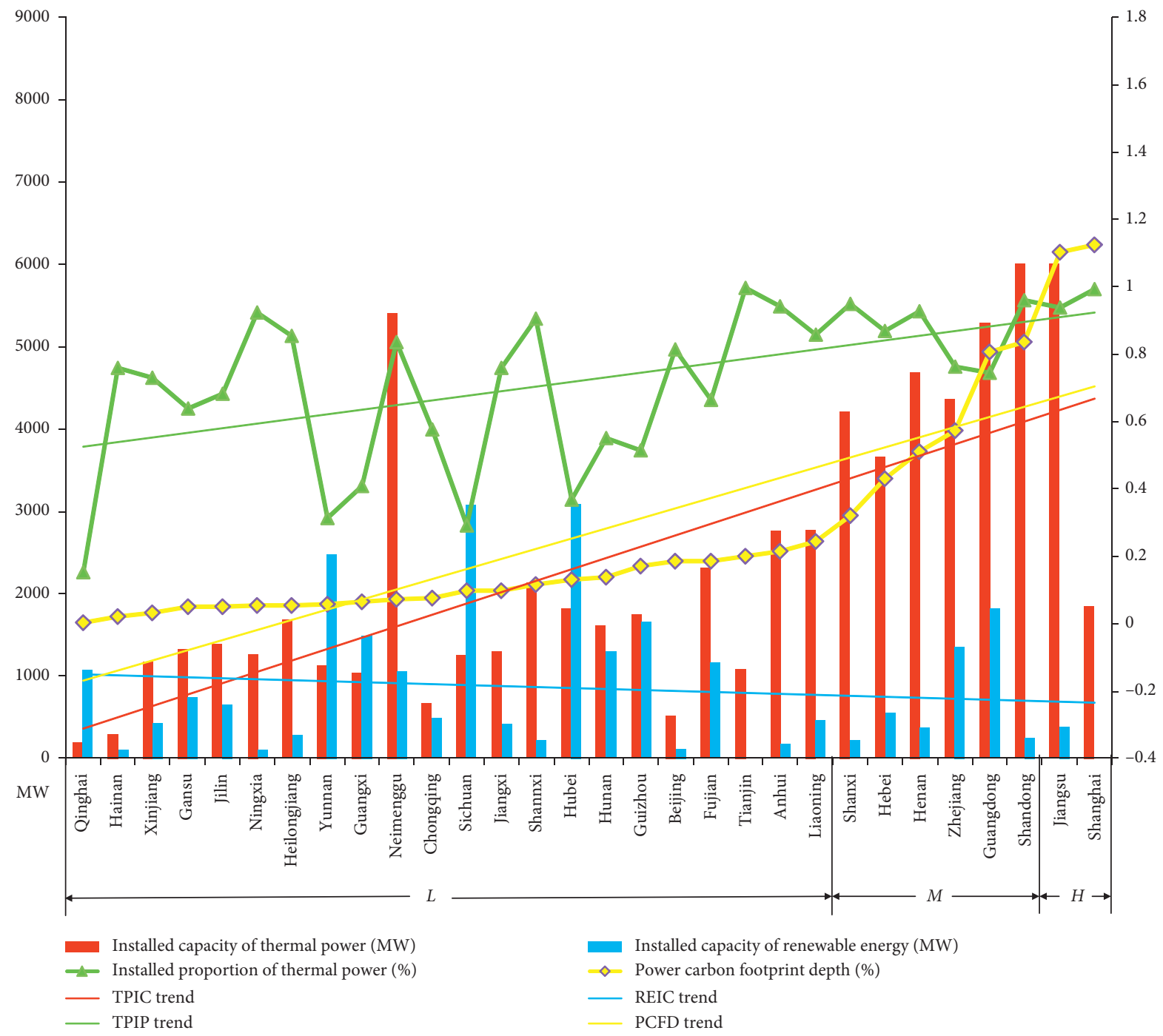

Figure 6: Power installation scale of China's provinces in 2008.

According to Figures 6 and 7, in 2008, the proportion of thermal power installed in most provinces of China is high. The proportion of thermal power installed in 24 provinces is higher than $50 \%$. In the $M$-level and $H$-level regions with a deep carbon footprint, the installed proportion of thermal power is more than $70 \%$. It can be seen that the installed capacity of thermal power in all provinces in 2018 has increased compared with 2008. Among the regions with the PCF depth of $M$, the installed capacity of thermal power exceeds 60\%; among the provinces with the PCF depth of $H$, the installed capacity of thermal power exceeds $80 \%$. In 2018 , the proportion of thermal power installed capacity in China's 20 provinces (cities) decreases. Among them, the renewable energy installed capacity in Gansu, Qinghai, Hubei, Sichuan, Yunnan, and Guangxi exceeds the installed capacity of thermal power. However, among these provinces (cities), only Yunnan and Sichuan have decreased their PCF depth.

As provided by Figures 6 and 7, the fitting curve slope of the regional PCF depth and thermal power installed capacity are principally equal. However, the fitting curve slope of the regional PCF and renewable energy installed capacity are quite different. Therefore, compared to renewable energy, the regional PCF is more affected by thermal power installations. By comparing the slope changes of the fitting curve of renewable energy installation in 2008 and 2018, we find that the depth of regional PCF is increasingly affected by the scale of renewable energy installation. Although China's installed capacity of renewable energy power is growing rapidly, the growth of the installed capacity of renewable energy is mainly concentrated in a few regions due to resource constraints. At present, renewable energy can effectively control the growth of PCF in these regions.

It is found through research that there is a strong positive correlation between the power CE and the installed capacity of thermal power under the current power demand level. For a specific region, its CE carrying capacity is certain in the short term. Hence, to ensure ecological safety, there should be an upper limit on the regional power $\mathrm{CE}$ and regional thermal power installed scale. 


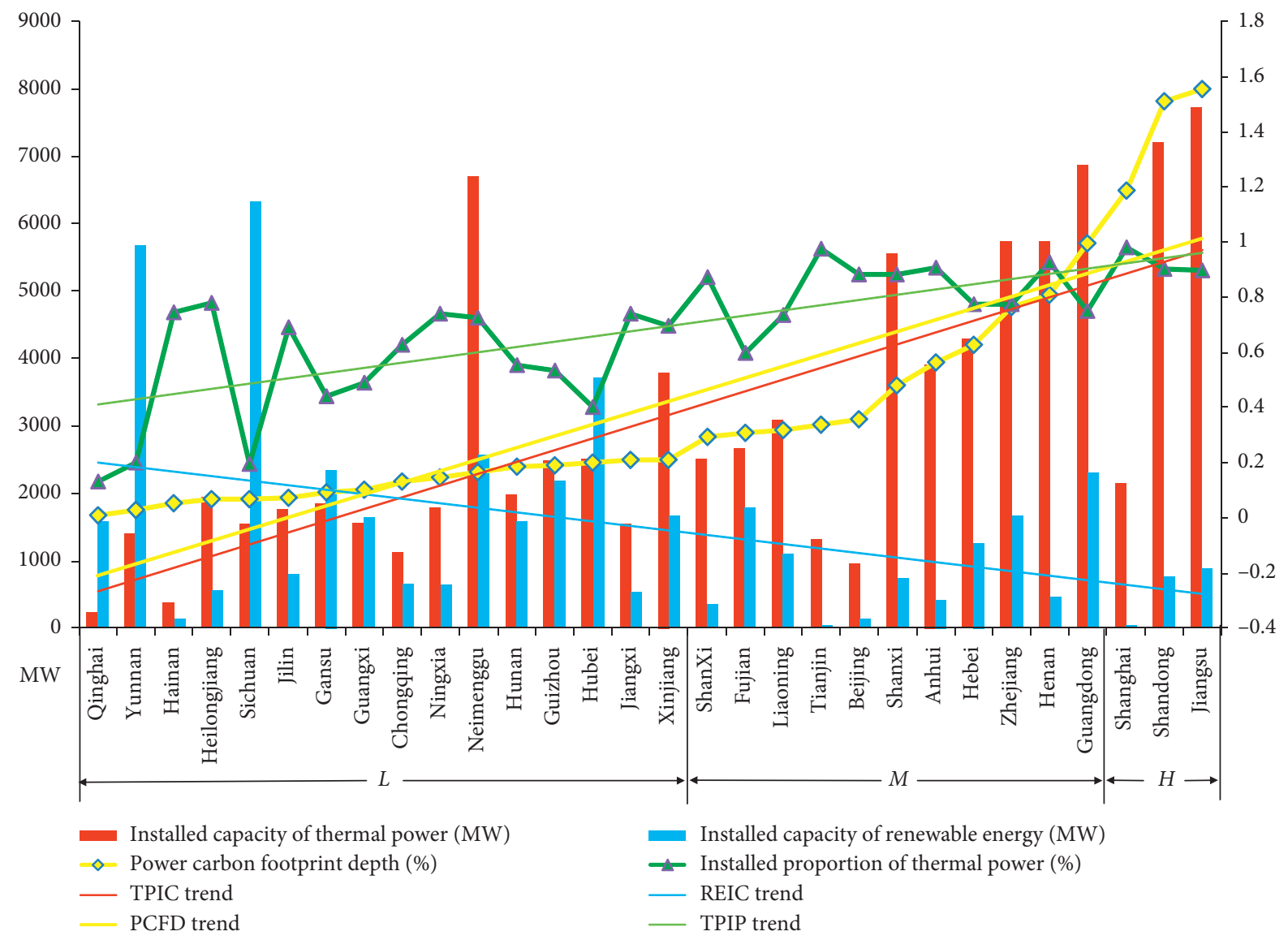

Figure 7: Power installation scale of China's provinces in 2018.

\section{Analysis of China's Power Carbon Deficit}

5.1. Measurement of China's Power Carbon Deficit. Referring to (2), (3), (11), and (12), China's regional power carbon deficit in 2008 and 2018 could be calculated. The results are shown in Figures 8 and 9, and the color depth of areas represents the degree of power carbon deficit. The arrows in the figures indicate the path of carbon footprint transfer, the starting point, and the terminal point, and the direction of the arrow depends on the actual transmission starting point and the direction of high-voltage transmission lines. The bar chart represents the power production structure of the power output provinces.

As shown in Figure 8, 12 provinces (cities) of China have power carbon deficits in 2008. Provinces (cities) with power carbon deficits exceeding 10 million MWh are Guangdong, Hebei, Beijing, Zhejiang, Shanghai, Jiangsu, Liaoning, and Tianjin. In 2008, there are 18 power output provinces in China, including nine provinces with power transmission capacity of more than 10 million MWh, which are ranked in order of power output, namely, Inner Mongolia, Hubei, Guizhou, Shanxi, Anhui, Yunnan, Sichuan, Shaanxi, and Guangxi. As can be seen in Figure 9, there are 16 provinces with power carbon deficit in 2018, including 13 provinces (cities) with deficit power exceeding 10 million MWh, which increase by Shandong, Henan, Chongqing, Hunan, and
Jiangxi compared with 2008. In 2018, there are 14 provinces with power output in China and ten provinces with the power output of more than 10 million MWh. According to the power output scale, they are Inner Mongolia, Sichuan, Yunnan, Guizhou, Shanxi, Hubei, Anhui, Xinjiang, Ningxia, and Gansu.

According to the installed ratio of thermal power (IRTP), annual utilization hours (AUH) of thermal power, and power carbon footprint depth (PCFD) in power deficit areas in 2008 and 2018, a comparison table of installed capacity of thermal power and depth of power carbon footprint in power deficit areas can be constructed (Table 2).

As illustrated in Table 2, in 2008 and 2018, the provinces with serious power deficit have a high installed ratio of thermal power, and the utilization rate of thermal power units in these provinces is far higher than the national average. Therefore, the high installed ratio and utilization rate of thermal power are the main reasons for the high depth of PCF in power deficit provinces.

5.2. Power Carbon Footprint Transfer. It can be seen from Figures 7 and 8 that there is a serious spatial mismatch between power generation and consumption in China. In northern China, the power deficit provinces are concentrated in Jing-Jin-Ji (Beijing-Tianjin-Hebei) region, and the 


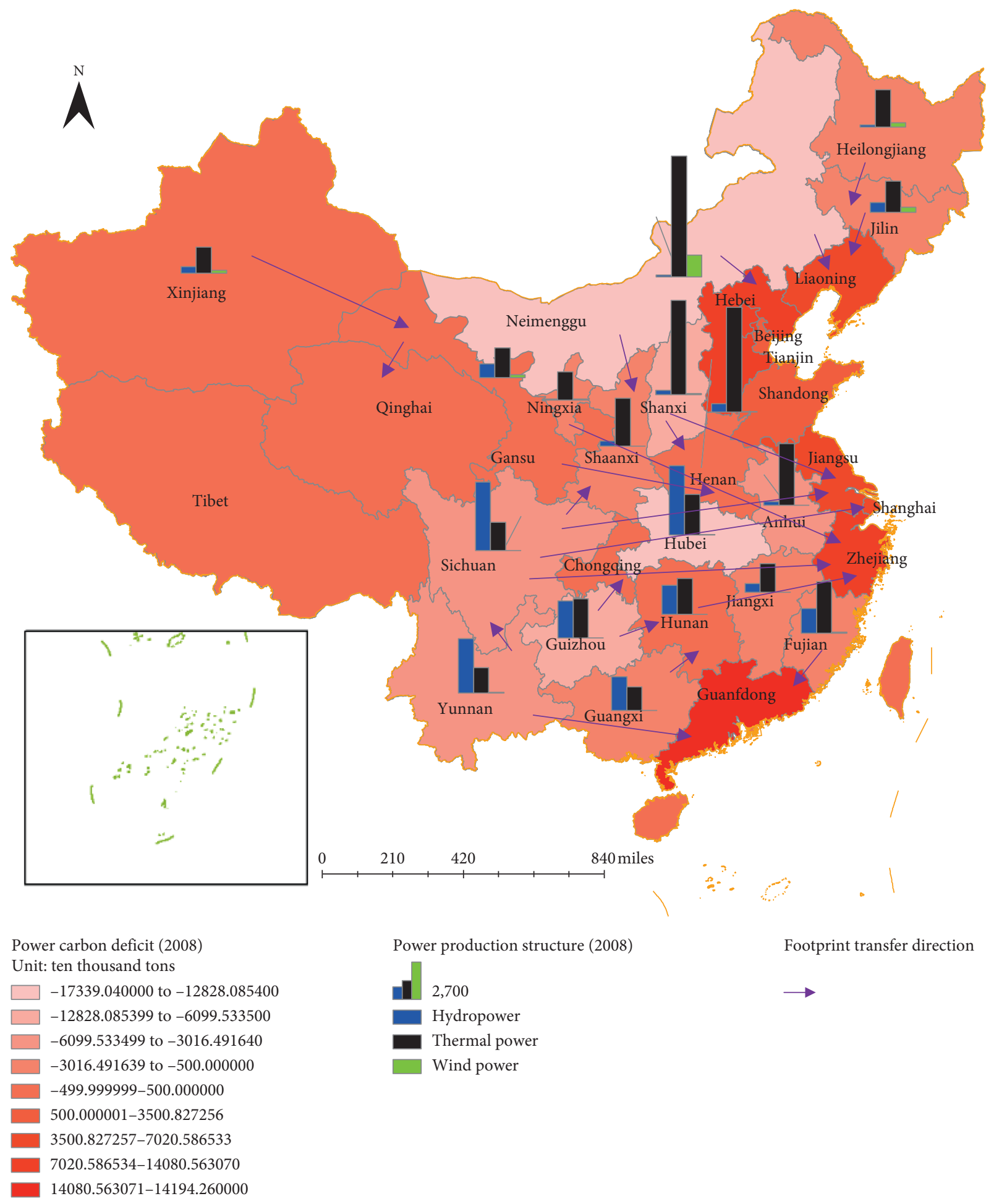

FIgURE 8: Distribution map of China's power carbon footprint deficit in 2008.

power output provinces are Inner Mongolia, Shanxi, Shaanxi, Ningxia, Gansu, and Xinjiang, which are dominated by thermal power installation. In southern China, the power deficit areas are mainly concentrated in Jiang-Zhe-Hu (Jiangsu, Zhejiang, Shanghai) region, and the power output provinces are mainly Yunnan, Sichuan, Guizhou, and Hubei provinces with hydropower installation. This pattern of supply and demand determines the transfer path of China's PCF. The main directions are from northwest to east, from southwest to east, and from southwest to south.

Besides, the transfer of PCF during power transmission also affects the depth of PCF in power-exporting provinces. The installed power in Northwest China is mainly thermal power. With the transfer of PCF, the carbon footprint of the 


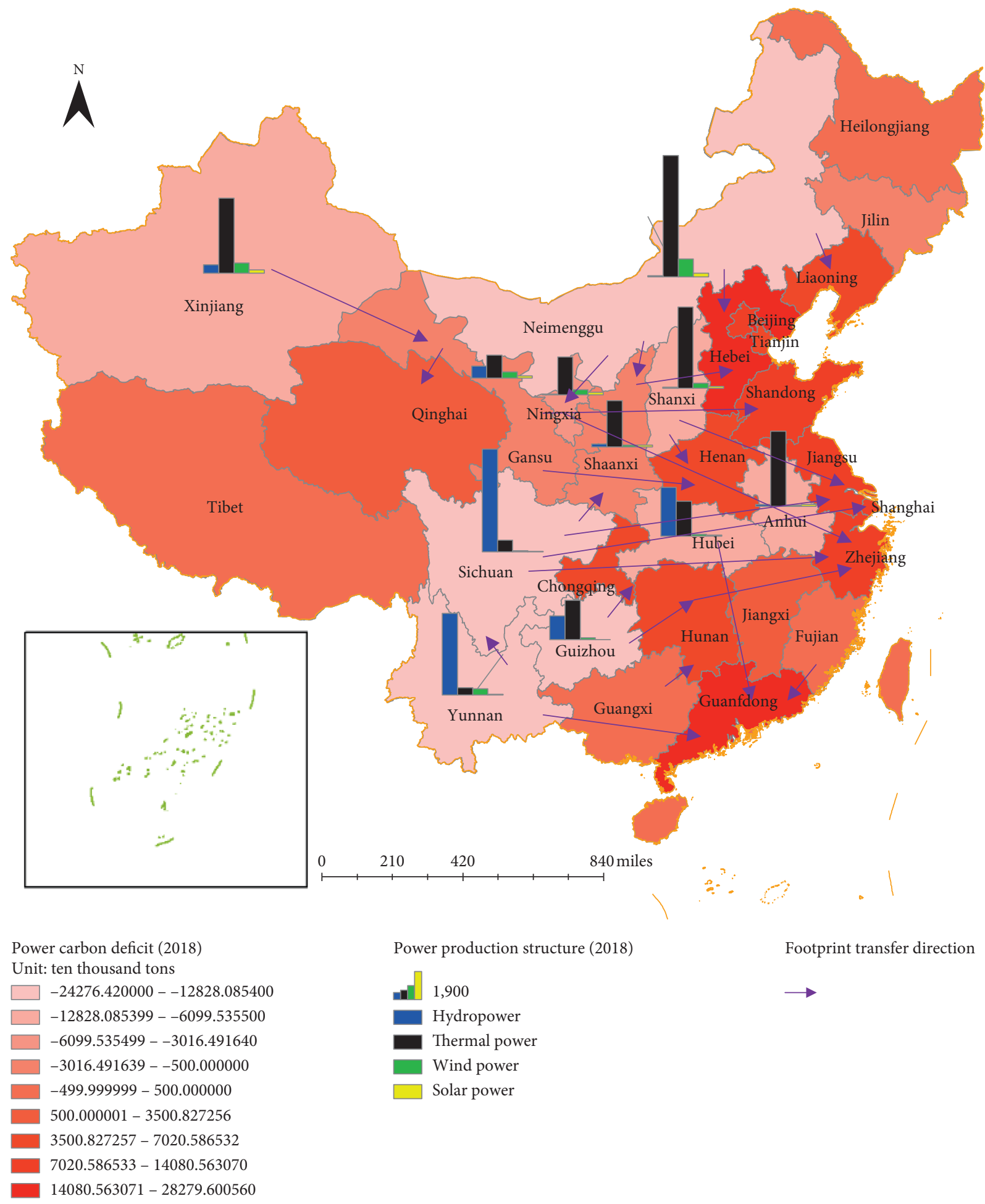

FIGURE 9: Distribution map of China's power carbon footprint deficit in 2018.

northwest regions is increased due to the increase of thermal power CE. The power output provinces of Southwest China mainly export clean energy power. In theory, renewable energy power production can replace part of thermal power production and to a certain extent improve the regional CE capacity. Therefore, a large number of hydropower resources in Southwest China are beneficial to the decrease of the regional PCF depth. As a result, the CE carrying capacity of the southwest region has increased, and the PCF depth has declined. 
TABle 2: TPIC and PCFD of China's power deficit provinces in 2008 and 2018.

\begin{tabular}{|c|c|c|c|c|c|c|}
\hline \multirow{2}{*}{ Deficit area } & \multicolumn{3}{|c|}{2008} & \multicolumn{3}{|c|}{2018} \\
\hline & IRTP (\%) & AUH (h) & PCFD (\%) & IRTP (\%) & AUH (h) & PCFD (\%) \\
\hline Liaoning & 85.87 & 4851 & 24.5 & 72.20 & 4251 & 31.81 \\
\hline Hebei & 86.93 & 5650 & 42.93 & 67.21 & 5056 & 62.89 \\
\hline Beijing & 81.46 & 3920 & 18.44 & 88.34 & 3754 & 35.90 \\
\hline Tianjin & 99.73 & 4325 & 20.06 & 93.49 & 4147 & 33.56 \\
\hline Shandong & 96.06 & 5410 & 83.71 & 82.31 & 4660 & 115 \\
\hline Henan & - & - & - & 83.29 & 3825 & 80.97 \\
\hline Chongqing & - & - & - & 66.35 & 3020 & 13.13 \\
\hline Hunan & - & - & - & 53.02 & 3564 & 18.65 \\
\hline Jiangxi & - & - & - & 61.05 & 5023 & 20.89 \\
\hline Jiangsu & 93.88 & 5469 & 110.22 & 83.77 & 4909 & 1.25 \\
\hline Shanghai & 99.19 & 4941 & 112.25 & 94.62 & 3731 & 118.85 \\
\hline Zhejiang & 76.21 & 5536 & 57.34 & 74.43 & 4165 & 76.39 \\
\hline Guangdong & 74.33 & 5338 & 80.56 & 78.93 & 4069 & 99.43 \\
\hline China & 75.87 & 3856 & 15.81 & 57.14 & 2010 & 28.77 \\
\hline
\end{tabular}

\section{Conclusions}

According to the CE of regional power production and the carrying capacity of the ecological environment, this paper built a PCF depth model to analyze the spatial and temporal differences of the regional PCF depth of China. The result shows that, firstly, the depth of China's PCF has increased year by year, and the gravity center of PCF depth moved eastward gradually. Due to the significant difference of thermal power production in different provinces (cities), the spatial difference in the depth of regional PCF was noticeable. Secondly, the correlation between the depth of regional PCF and the installed capacity of regional thermal power was more significant than that of regional renewable energy, and the impact of regional renewable energy installed capacity on the depth of regional PCF was increasingly influential. Thirdly, more than half of China's provinces (cities) had power carbon deficit in 2018, and the deficit level was much higher than that of 2008. The regions with serious power carbon deficit were also with high PCF depth, and the installed proportion and utilization hours of thermal power in these regions were much higher than those of other regions.

Based on the analysis of the spatial and temporal differences in the depth of China's regional PCF, this paper proposes the following suggestions: (1) Control the scale of thermal power installations in the central and eastern regions to reduce the regional environmental pressures by decreasing approval and accelerating decommissioning old thermal power units. (2) Vigorously develop renewable energy in the provinces (cities) with severe power deficits, and guide high-energy-consuming industries shift from the power deficit provinces (cities) to the areas with abundant power production. (3) Avoid the excessive development of hydropower resources and increase the proportion of wind power and photovoltaic power generation in Southwest China. (4) Optimize the carbon footprint transfer path, and improve the consumption level of wind power and photovoltaic in Northwest China.
The proposed PCF depth model can scientifically evaluate the pressure of regional power production on the environment and can be used to analyze the impact of power production, transmission, and consumption on the regional ecological environment. The results of this study can provide references for formulating emission reduction policies and optimizing the power structure. The model and method can also be used to analyze the energy and environmental problems for other countries.

\section{Data Availability}

The data used to support the findings of this study are available from the corresponding author upon request.

\section{Conflicts of Interest}

The authors have no conflicts of interest to declare.

\section{Acknowledgments}

This study was funded by the Beijing Natural Science Foundation (8192043).

\section{References}

[1] IEA, "World energy outlook 2018 London," 2018, http://www. iea.org/weo/weo2018/secure/.

[2] CAT, "CAT emissions GAP," 2019, https:// climateactiontracker.org/countries/china/.

[3] China and the Unit States, China US Joint Statement on Climate Change, Beijing, China, November 2014.

[4] Z.-Y. Zhao, Y.-L. Chen, and R.-D. Chang, "How to stimulate renewable energy power generation effectively?-China's incentive approaches and lessons," Renewable Energy, vol. 92, pp. 147-156, 2016.

[5] China Electricity Council and American Environmental Protection Association, "Research on the progress of carbon emission trading market in China's power industry-research on China's power emission reduction," 2018, http://www. tanjiaoyi.com/article-26959-1.html. 
[6] I. Khan, "Power generation expansion plan and sustainability in a developing country: a multi-criteria decision analysis," Journal of Cleaner Production, vol. 220, pp. 707-720, 2019.

[7] D. Nock and E. Baker, "Holistic multi-criteria decision analysis evaluation of sustainable electric generation portfolios: New England case study," Applied Energy, vol. 242, pp. 655-673, 2019.

[8] M. T. De Silva, G. M. Hornberger, and H. Baroud, "Decision analysis to support the choice of a future power generation pathway for Sri Lanka," Applied Energy, vol. 240, pp. 680-697, 2019.

[9] T. Wiedmann and J. Minx, "A definition of 'carbon footprint'," in Ecological Economics Research Trends, C. C. Pertsova, Ed., pp. 1-11, Nova Science Publishers, Hauppauge, NY, USA, 2008.

[10] G. Hammond, "Time to give due weight to the 'carbon footprint' issue," Nature, vol. 445, no. 7125, p. 256, 2007.

[11] G. Stoeglehner and M. Narodoslawsky, "How sustainable are biofuels? Answers and further questions arising from an ecological footprint perspective," Bioresource Technology, vol. 100, no. 16, pp. 3825-3830, 2009.

[12] G. Stoeglehner, J. K. Levy, and G. C. Neugebauer, "Improving the ecological footprint of nuclear energy: a risk-based lifecycle assessment approach for critical infrastructure systems," International Journal of Critical Infrastructures, vol. 1, no. 4, p. 394, 2005.

[13] C.-Z. Chen and Z.-S. Lin, "Multiple timescale analysis and factor analysis of energy ecological footprint growth in China 1953-2006," Energy Policy, vol. 36, no. 5, pp. 1666-1678, 2008.

[14] N. Santhanam, "Increasing India's wind energy footprint," PowerWatch INDIA, pp. 66-69, 2011, http://www.eai.in.

[15] N. Brown, "Ongoing case: solar energy PEIS: case digest: section 106 in action, Advisory Council on Historic Preservation," 2009, http://www.achp.gov.

[16] A. Galli, T. Wiedmann, E. Ercin et al., "Integrating ecological, carbon and water footprint into a "footprint family" of indicators: definition and role in tracking human pressure on the planet," Ecological Indicators, vol. 16, pp. 1-112, 2012.

[17] M. Wackernagel, "Our ecological footprint: reducing human impact on the earth," Population \& Environment, vol. 1, no. 3, pp. 171-174, 1995.

[18] M. Wackernagel and W. E. Rees, Our Ecological Footprint: Reducing Human Impact on the Earth, New Society Publishers, Gabriola Island, Canada, 1996.

[19] J. Wei, K. Huang, S. Yang, Y. Li, T. Hu, and Y. Zhang, "Driving forces analysis of energy-related carbon dioxide (CO2 ) emissions in Beijing: an input-output structural decomposition analysis," Journal of Cleaner Production, vol. 163, pp. 58-68, 2017.

[20] N. Ding and J. Yang, "Life cycle inventory analysis of fossil energy in China," China Environmental Science, vol. 35, no. 5, pp. 1592-1600, 2015.

[21] B. Zhang, X. Qu, J. Meng, and X. Sun, "Identifying primary energy requirements in structural path analysis: a case study of China 2012," Applied Energy, vol. 191, pp. 425-435, 2017.

[22] J. Franz and E. Papyrakis, "Online calculators of ecological footprint: do they promote or dissuade sustainable behaviour?" Sustainable Development, vol. 19, no. 6, pp. 391-401, 2011.

[23] L. L. Lou, H. L. Mu, X. Chen, and H. N. Li, "The carbon footprint analysis of thermal power plants," Advanced Materials Research, vol. 807-809, pp. 814-821, 2013.

[24] B. X. Sun, X. Z. Gong, Y. Liu, W. J. Chen, and Z. H. Wang, "Matrix-based model of the carbon footprint analysis for thermal power generation in China," Materials Science Forum, vol. 685, pp. 230-238, 2011.

[25] Z. J. Wang and K. Fang, "Estimation of China's power carbon footprint based on the characteristics of source diversity," Journal of Electric Power (Chinese), vol. 27, no. 2, pp. 158-162, 2012.

[26] Y. Wang and S. P. Gu, "Analysis of China's electricity carbon footprint and its ecological pressure during 2006-2015," Journal of Environmental Science (Chinese), vol. 38, no. 12, pp. 4873-4878, 2018.

[27] K. Fang, X. J. Zhu, K. Gao et al., "Carbon footprint of global electric power and its equivalent factor calculation," Journal of Ecology (Chinese), vol. 31, no. 12, pp. 3160-3166, 2012.

[28] M. Zhai, G. Huang, L. Liu, B. Zheng, and Y. Guan, "Interregional carbon flows embodied in electricity transmission: network simulation for energy-carbon nexus," Renewable and Sustainable Energy Reviews, vol. 118, p. 109511, 2020.

[29] X. Li, S. Xiong, Z. Li, M. Zhou, and H. Li, "Variation of global fossil-energy carbon footprints based on regional net primary productivity and the gravity model," Journal of Cleaner Production, vol. 213, pp. 225-241, 2019.

[30] Y. Zhang, J. Fang, S. Wang, and H. Yao, "Energy-water nexus in electricity trade network: a case study of interprovincial electricity trade in China," Applied Energy, vol. 257, Article ID 113685, 2020.

[31] Development and Reform Commission of the PRC, "Guidelines for the preparation of provincial greenhouse gas inventories," 2011, https://wenku.baidu.com/view/ 5374dfdd50e2524de5187e74. html/.

[32] Y. Long, Study on Calculation Model and Method of Carbon Dioxide Emissions for Coal-Fired Power Plant, Chongqing University, Chongqing, China, 2016.

[33] K. Fang, D. M. Dong, and Z. Lin, "Calculation method of energy ecological footprint based on global net primary productivity," Acta Ecologica Sinica, vol. 32, no. 9, pp. 2900-2909, 2012.

[34] K. Fang and W. B. Shen, "Construction and application of calculation model for C02 emission carrying capacity," Ecological Science (Chinese), vol. 29, no. 6, pp. 588-562, 2010.

[35] K. Fang, W. B. Shen, Q. M. Zheng et al., "Ecological carrying capacity of fossil energy land," Environmental Science \& Technology (Chinese), vol. 34, no. 12, pp. 201-205, 2011.

[36] W. E. I. Jing and W.-h. Zeng, "Dynamic simulation of regional sustainable development under the restriction of eco-capacity-a case study in boao planning area," China Environmental Science, vol. 29, no. 3, pp. 330-336, 2009.

[37] Power Reliability Management Center, "National generator set manual," Report, Power Reliability Management Center, Beijing, China, 2018, https:/xueqiu.com/2733868088/133633258.

[38] National Bureau of Statistics, "China statistical yearbook," 2020, http://www.stats.gov.cn/.

[39] China Electricity Council, "China's power industry development report," Report, China Electricity Council, Beijing, China, 2018.

[40] China Electricity Council, "Statistical data collection of electric power industry," 2018, http://tongji.cnki.net/kns55/ navi/HomePage.aspx?floor=1\&id=N2016040088\& name $=$ YDLGT $/$.

[41] ESRI, arc GIS resources: arc GIS HELP 10.1: average center (spatial statistics), http://resources.arcgis.com/zh-cn/help/ main/10.1/index.html\#/na/005p00000018000000/>. 